\title{
MERCURY ADSORPTION BY ARTHOBACTER GLOBIFORMIS AND SPIRULINA PLATENSIS
}

\author{
T. L. Kalabegishvili1, ${ }^{1,2}$ I. Murusidze², D. T. Pataraya ${ }^{3}$, E. Ginturi ${ }^{1}$, M. V. Frontasyeva ${ }^{4}$, E. I. \\ Kirkesali $^{1}$, Gh. Duca ${ }^{5}$ I. Zinicovscaia ${ }^{4,5^{*}}$ \\ ${ }^{1}$ Andronikashvili Institute of Physics, 6, Tamarashvili Str., Tbilisi, 0177, Georgia \\ ${ }^{2}$ Ilia State University, 3/5, K. Cholokashvili Ave., Tbilisi 0162, Georgia \\ ${ }^{3}$ Durmishidze Institute of Biochemistry and Biotechnology, D. Agmashenebeli Kheivani, $10 \mathrm{~km}$, 0159, Tbilisi, Georgia \\ ${ }^{4}$ Joint Institute for Nuclear Research, Joliot-Curie Str., 6, 1419890 Dubna, Russia \\ ${ }^{5}$ The Institute of Chemistry of the Academy of Sciences of Moldova, 3, Academiei Str., 2028 Chisinau, R. Moldova \\ E-mail: zinikovskaia@mail.ru
}

\begin{abstract}
The increasing contamination of soil, sediment, and water with heavy metals by natural and industrial processes is a worldwide problem. Many bacteria and microalgae have demonstrated ability to absorb toxic elements. To study mercury biosorption by bacteria Arthrobacter globiformis and microalga Spirulina platensis neutron activation analysis (NAA) was applied. The process of mercury biosorption by these media was described by Freundlich and Langmuir-Freundlich Model. Both microorganisms showed a great potential to be used as biosorbing agents for mercury removal from the environment.
\end{abstract}

Keywords: Langmuir-Freundlich model, Arthrobacter globiformis, Spirulina platensis, biosorption, mercury, neutron activation analysis.

\section{Introduction}

Heavy metals are known as a hazardous group of pollutants. The contamination by heavy metals causes a serious problem because they cannot be naturally degraded like organic pollutants and they are accumulated in different parts of the food chain [1]. Physical and chemical methods have been proposed for the removal of these pollutants. Nevertheless, they have some disadvantages, among them cost-effectiveness limitations, generation of hazardous by-products or inefficiency when concentration of polluted materials is below $100 \mathrm{mg} / 1$ [2]. Biological methods help to avoid these drawbacks since they are easy to operate, do not produce secondary pollution and show higher efficiency at low metal concentrations. Microorganisms and plants are usually used for the removal of heavy metals. Mechanisms by which microorganisms act on heavy metals include biosorption, bioleaching, biomineralization, intracellular accumulation and enzyme-catalyzed transformations [3].

Mercury occupies the sixth position in the list of hazardous compounds [4-7]. Even its very small doses cause gonadotoxic, mutagenic, neurotoxic and embryotoxic effects. Accumulating mainly in the kidneys, liver and spleen, mercury blocks the biochemical activity of protein molecules and low-molecular weight compounds.

Mercury is a well-distributed element. Its mean content in the earth's crust constitutes $8 \times 10^{-60} \%$. The total amount of mercury in the atmosphere is $10^{-9} \mathrm{~g} / \mathrm{m}^{3}, 1 \times 10^{-60} \%$ in soil, and $25 \times 10^{-60} \%$ in plants (dry mass) [8].

Mercury is widely used in industry, medicine, dentistry, batteries, science, and in military applications. Mercurial compounds are also used in agriculture as insecticides, fungicides, herbicides and bactericides [9]. These various industrial and agricultural applications have led to severe mercury localized pollution in the aquatic systems and in soils [10-11]. To prevent the detrimental effects of mercurial compounds, many bacterial species Alteromonas tagae sp. nov., Alteromona simiduii sp. nov [5], Klebsiella pneumonia, Streptomyces sp. have evolved a sophisticated detoxification system by which $\mathrm{Hg}(\mathrm{II})$ can be reduced to $\mathrm{Hg}(0)$ followed by volatilization of the relatively non-toxic $\mathrm{Hg}$ (0) from aqueous media [7].

Algae have been successfully used for waste, wastewater and soil treatment. Chlorella pyrenoidosa, Oedogonium foveolatum, Hydrodictyon reticulatum, Scenedesmus quadricauda, Spirulina platensis, Spirulina maxima, Mastigocladus laminosus efficiently remove aluminum, mercury, cadmium, zinc and chromium from wastes [12]. S. platensis can be used as a metal adsorbent to accumulate copper, mercury, lead [13-14], chromium [15], and cadmium [16]. Scenedesmus acutus and Chlorella vulgaris can be used to accumulate cadmium, zinc and chromium from wastewater [17].

In this work, biosorption of mercury by Arthrobacter globiformis and Spirulina platensis using neutron activation analysis was studied.

\section{Material and methods}

\section{Sample preparation}

Cultivation of Arthrobacter globiformis 151B

Samples of Arthrobacter globiformis 151B a Gram-positive, $\mathrm{Cr}(\mathrm{VI})$-reducer, aerobic bacterial strain was isolated from basalt samples collected from the most polluted region in the Republic of Georgia (Kazreti). The bacteria were 
grown aerobically in the following nutrient medium: $10 \mathrm{~g}$ of glucose, $10 \mathrm{~g}$ of peptone, $1 \mathrm{~g}$ of yeast extract, $2 \mathrm{~g}$ of caseic acid hydrolysate, $5 \mathrm{~g}$ of $\mathrm{NaCl}$, and 1 liter of distilled water. All chemicals used in the experiment were ACSreagent grade, produced by Sigma (St. Louis, MO, USA). Bacterial cells were grown in $250 \mathrm{ml}$ Erlenmayer flasks as a suspension. The medium was inoculated with $0.1 \mathrm{ml}$ of overnight broth and incubated at $21{ }^{\circ} \mathrm{C}$ being shaken continuously. $\mathrm{Hg}$ (II) as $\left[\mathrm{Hg}\left(\mathrm{NO}_{3}\right)_{2} \cdot \mathrm{H}_{2} \mathrm{O}\right]$ was added to the bacterial cell cultures at an early stationary phase of their growth. The concentration of $\mathrm{Hg}(\mathrm{II})$ varied within the range of 50-5000 $\mu \mathrm{g} / \mathrm{L}$. After being cultivated for 5 days the cells were harvested by centrifugation $\left(10,000 \mathrm{rpm}, 15 \mathrm{~min}, 4^{\circ} \mathrm{C}\right)$, rinsed twice in a $20 \mathrm{mM}$ phosphate buffer and subjected to NAA analysis. For NAA measurements this wet biomass was placed in an adsorption-condensation lyophilizer and dried. The dry native biomass was finally pelletized to $5 \mathrm{~mm}$ pieces using a special titanium press form [18].

Cultivation of Spirulina platensis

Spirulina platensis IPPAS B-256 strain from Timiriazev Institute for Plant Physiology of the Russian Academy of Sciences was cultivated in a standard Zaroukh alkaline water-salt medium at a temperature of $+34^{\circ} \mathrm{C}$, illumination $\sim 5000$ lux, initial pH 8.7 and at constant mixing. Since the $\mathrm{Hg}(\mathrm{II})$ ions in alkaline medium form an insoluble residue (mercury hydroxide), in order to avoid the mercury residue, mercury glycinate was used as a nutrient loading. To study the $\mathrm{Hg}$ accumulation by the S. platensis cells the concentrations of nutrient medium loading by mercury constituted 100 , $50,5,1,0.1 \mu \mathrm{g} \mathrm{Hg} / \mathrm{L}$. Initial concentration of $S$. platensis suspension in all the experiments of the series constituted $260 \mathrm{mg} / \mathrm{L}$. Cultivation of the S. platensis cells was conducted for 6 days. Samples in all the series were taken every 24 hours. In the course of all the experiments microscopic control of S. platensis living cells was performed daily [8].

\section{Analysis}

The Arthrobacter globiformis 151B samples were irradiated using the facilities of the $2 \mathrm{MW}$ nuclear research reactor "Hoger Onderwijs Reactor" of the Reactor Institute Delft, Delft University of Technology [18]. More details on the operation and quality assurance in this laboratory can be found elsewhere [19-20]. Mercury content in the Spirulina platensis samples was determined by epithermal neutron activation analysis (ENAA) at the pulsed fast reactor IBR-2 (FLNP JINR, Dubna) [8]. The description of irradiation channels and pneumatic transport system of the IBR-2 are given in [21]. The ENAA data processing and determination of $\mathrm{Hg}$ concentrations were performed using software developed in FLNP JINR [22].

\section{Results and discussion}

Two heterogeneity-based models isotherm: Freundlich and Langmuir-Freundlich isotherm model (LF) were used for the evaluation of the sorption characteristic of mercury on bacteria Arthrobacter globiformis and microalga Spirulina platensis.

Freundlich isotherm model

NAA results obtained for Spirulina platensis were expressed by Freundlich (heterogeneous) isotherm model (Fig. 1). The Freundlich equation is often considered to be purely empirical in nature [23].

The Freundlich Adsorption Isotherm is mathematically expressed as

It is also can be written as

$$
x / m=K c^{1 / n}
$$

$$
\log (x / m)=\log K+(1 / n) \log c
$$

where: $\mathrm{x}=$ mass of adsorbate; $\mathrm{m}=$ mass of adsorbent; $\mathrm{c}=$ equilibrium concentration of adsorbate in solution; $\mathrm{K}$ and $\mathrm{n}$ are constants for a given adsorbate and adsorbent at a particular temperature.

In work [8] theoretical calculations of the adsorption isotherm for $\mathrm{Hg}$ (II) on the basis of the obtained experimental data were performed taking into account both physical adsorption and chemosorption. For various $\mathrm{Hg}$ (II) concentrations at the duration of cultivation for 24 hours in the Freundlich coordinates the dependence was obtained

$$
\log R=-6.77+0.62 \log C
$$

where $\mathrm{R}$ - concentration of the adsorbed $\mathrm{Hg}(\mathrm{II}), \mathrm{C}$ - concentration of $\mathrm{Hg}(\mathrm{II})$ in nutrient medium.

Linear approximation by method of least squares is shown in (Fig. 1). The straight line is cutting off on the $\mathrm{Y}$-axis a section, equal to $\log \mathrm{K}$. In the present case $\log \mathrm{K}=-6.77$ and $\mathrm{K}=0.17 \cdot 10^{-6}$. The correlation coefficient is $\mathrm{R}=$ 0.97 . The obtained result can be regarded as a confirmation of predominance of biosorptive processes at the initial stage of the $S$. platensis cell cultivation. 


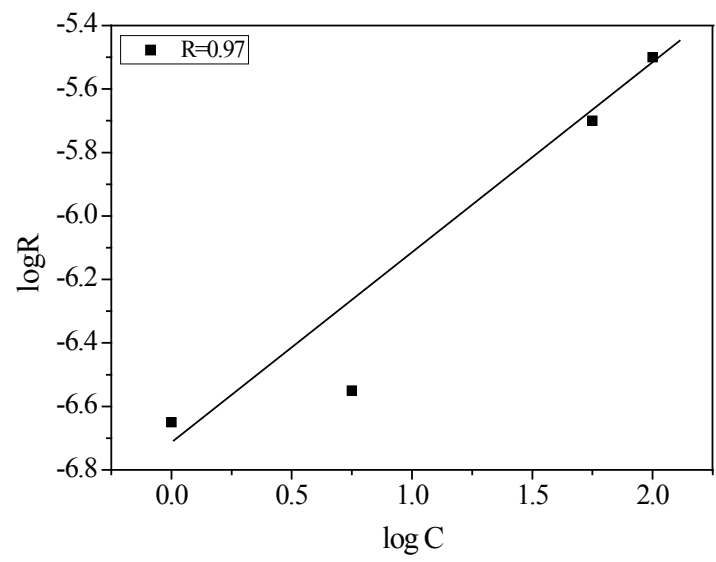

Fig. 1. Freundlich diagram. Linear approximation by method of least squares

The cell surface of many microorganisms, including cyanobacteria, consists of polysaccharides, proteins, and lipids, which act like basic binding sites of heavy metals because they have functional groups, such as amino, carboxylic, sulfhydryl, phosphate, and thiol groups, which can bind metals. The cell wall of Spirulina platensis consists of polysaccharides, proteins, and lipids, which have many negative carboxyl and phosphate groups, the dominant binding sites of toxic and heavy-metal cations [24].

It was shown that carboxyl groups of alginate played a major role in the complexation of heavy metals [25].

\section{Langmuir-Freundlich isotherm model}

Langmuir isotherm (L) is a useful model to represent the sorption mechanism. This model is based on the assumption that the sorption energy is uniform and homogeneously distributed on the sorbent surfaces.

The Langmuir isotherm model is expressed as:

$$
q=q_{\max } b c / 1+b c
$$

Here: $c$ - is the concentration of metal ions; $q_{\max }$ - represents the maximum metal accumulation; $b$ - is the affinity parameter of the isotherm reflecting the high affinity of the biosorbent for the sorbate.

The theoretical assumption of the Langmuir model is that the bonding energy on each sorption site is completely equal [22]. The metal uptake (q) was calculated from the initial concentration $\left(\mathrm{C}_{\mathrm{i}}\right)$ and the analyzed final concentration $\left(\mathrm{C}_{\mathrm{f}}\right)$ of the metal in solution according to the following formula:

$$
q=V\left(C_{i}-C_{j}\right) / m
$$

where $\mathrm{V}$ is the liquid sample volume and $\mathrm{m}$ is the starting sorbent weight [18].

Some experimental results showed that the theoretical assumption of the Langmuir model failed to explain the sorption of some compounds.

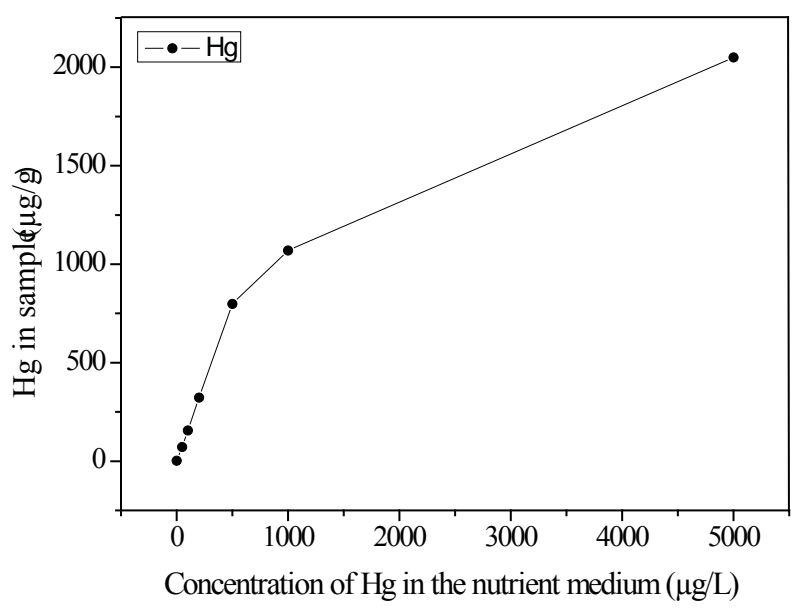

Fig. 2. Accumulation of mercury by A. globiformis 
Thus, the heterogeneity of sorption energy has been taken into account. The heterogeneity-based isotherm, the Langmuir-Freundlich isotherm model (LF), is then derived as [26].

$$
q=q_{\max }(b c)^{n} / 1+(b c)^{n}
$$

where $\mathrm{n}$ is related to the degree of heterogeneity of a sorbent surface.

Langmuir-Freundlich isotherm was used to describe process of mercury accumulation by bacteria A. globiformis (Fig. 2) [18].

Adsorption processes consists of two steps, starting with the rapid one (physical adsorption between the metal ions and the bacterial surface) and continuing with the slow one (chemical adsorption). The rapid process one may last from for several minutes to a few hours, while the slow one lasts from several hours to a few days. The metallic cations form complexes with functional groups (carboxyl, carbonyl, amino, amido, sufonate, phosphate, etc.) present on the surface or inside the porous structure of the biological material [27].

\section{Conclusions}

It was shown that the mercury accumulation process fits well the Freundlich and Langmuir-Freundlich models. This is obvious evidence that the bacteria Arthrobacter globiformis and microalga Spirulina platensis can be successfully used as biosorbing agent for mercury removal from the environment.

\section{References}

[1]. Љmejkalová, M.; Mikanová, O.; Borůvka, L. Plant Soil Environ. 49, 2003, 7, 321-326.

[2]. Wang, J.; Chen, C. Biotechnology Advances. 2009, 27, 195- 226.

[3]. Haferburg, G.; Kothe, E. J. Basic Microbiol. 2007, 47, 453-467.

[4]. Oliveira, A.; Pampulha, M. E.; Neto, M. M.; Almeida, A. C. Geoderma. 2010, 154, 359-363.

[5]. Chiu, H.-H.; Shieh, W. Y.; Lin, S. Y.; Tseng, C. M.; Chiang, P.W.; Wagner-Dobler, I. Intern. J. of Syst. and Evol. Microbiol. 2007, 57, 1209-1216.

[6]. Olson, B. H.; Cayless, S. M.; Ford, S.; Lester, J. N. Arch. Environ. Contam. Toxicol. 1991, 20, $226-233$.

[7]. Zeroual, Y.; Moutaouakkil, A.; Dzairi, F.Z.; Talbi, M.; Chung, P.U.; Lee, K.; Blaghen, M. Ann. Microbiol. 2003, 53, 149-160.

[8]. Frontasyeva, M. V.; Kirkesali, E. I.; Aksenova, N. G.; Mosulishvili, L. M.; Belokobylsky, A. I.; Khizanishvili, A. I. J. Neutron Res. 2006, 14, $131-137$.

[9]. Essa, A. M. M.; Macaskie, L. E., Brown, N. L. Biochem. Soc. Trans. 2002, 30(4), 672-674.

[10]. Bargagli, R. Encyclopedia of environmental science. Kluwer Academic Publisher, 1999, pp.402-405.

[11]. Bryan, G.W.; Langston, W. J. Environ. Pollut. 1992, 76, 84-131.

[12]. Radway, J. C.; Wilde, E. W.; Whitaker, M. J.; Weissman, J. C. J. Appl. Phycol. 2001, 13, 451-455.

[13]. Disyawongs, G. J. KMITNB. 2002, 12, 4-8.

[14]. Solisio, C.; Lodi, A.; Torre, P.; Converti, A.; Del Borghi, M. Bioresource Technol. 2006, 97, $1756-1760$.

[15]. Mosulishvili, L. M.; Belokobylsky, A. I.; Kirkesali, E. I.; Frontasyeva, M. V.; Pavlov, S. S.; Aksenova, N. G. J. Neutron Res. 2007, 15(1), 49-54.

[16]. Solisio, C.; Lodi, A.; Soletto, D.; Converti, A. Bioresource Technol. 2008, 99, 5933-5937.

[17]. Travieso, L.; Cañizares, R. O.; Borja, R.; Benítez, F.; Domínguez, A. R.; Dupeyrón, R.; Valiente, V. Bull. Environ. Contam. Toxicol. 1999, 62, 144-151.

[18]. Tsibakhashvili, N., Mosulishvili, L., Kirkesali, E.; Murusidze, I.; Frontasyeva, M. V.; Pavlov, S. S.; Zinicovscaia, I. I.; Bode, P.; van Meerten, Th. G. J. Radioanal. Nucl. Chem. 2010, 286, 533-537.

[19]. Bode, P. J. Radioanal. Nucl. Chem. 2000, 245,127-132.

[20]. Koster-Ammerlaan, M.J.J.; Bode, P. J. Radioanal. Nucl. Chem. 2009, 280,445-449.

[21]. Frontasyeva, M.V.; Pavlov, S.S. JINR Preprint E14-2000-177, Dubna, 2000.

[22]. Ostrovnaya, T.M.; Nefedyeva, L.S.; Nazarov, V.M.; Borzakov, S.B.; Strelkova, L.P. Software for INAA on the basis of relative and absolute methods using nuclear database. In «Activation Analysis in Environment Protection». D-14-93-325, 1993, Dubna, 319-326.

[23]. Hussain, A.; Ghafoor, A.; Anwar-ul-Haq, M.; Nawaz, M. Int. J. Agr. Biol. 2003, 5(3), 349-356.

[24]. Dheetcha, A.; Mishra, S. Curr. Microbiol. 2008, 57, 508-514.

[25]. Pan, J.; Lin, R.; Ma, L. Chinese Journal of Oceanology and Linmology. 2000, 18 (3), 260- 264

[26]. Tsai, S. C.; Juang, K. W.; Jan, Y. L. J. Radioanal. Nucl. Chem. 2005, 266 (1), 101-105.

[27]. Fourest, E.; Volesky, B.; 1997. Appl. Biochem. Biotechnol. 1997, 67, 215 - 226. 